Letrônica, Porto Alegre, v. 7, n. 1, p. 47-65, jan./jun., 2014

\title{
MEMÓRIA LEXICAL E SEMÂNTICA DE BILÍNGUES
}

\author{
BILINGUAL LEXICAL AND SEMANTIC MEMORY
}

\author{
Pâmela Freitas Pereira Toassi* \\ Mailce Borges Mota**
}

\begin{abstract}
Resumo: As questões relacionadas à organização e à representação mental do léxico de bilíngues são desafiadoras para pesquisadores interessados em investigar a aprendizagem de língua estrangeira. Pesquisas relacionadas à memória das palavras das duas línguas de bilíngues apresentam resultados diversos, o que aumenta a intensidade do debate. De um lado pesquisadores defendem uma armazenagem compartilhada para os léxicos da primeira e da segunda língua, porém, outros defendem uma armazenagem separada. Diante desse debate, há também questões relativas à ativação das duas línguas durante a produção lexical dos bilíngues. Desta forma, este trabalho pretende revisar dois modelos de memória lexical e semântica de bilíngues (RHM e BIA+) e estudos relacionados, com o objetivo de compreender se a memória semântica das duas línguas do bilíngue é representada de forma integrada.
\end{abstract}

Palavras-chave: Memória lexical; Memória semântica; Léxico de bilíngues; Modelos de memória lexical de bilíngues.

\begin{abstract}
Issues regarding the organization and processing of the bilingual mental lexicon present a challenge for researchers interested in investigating second language acquisition. Research related to the memory of words for the bilingual's two languages present different results, which intensify this debate. On one side of this debate, researchers support a theory that there is a shared storage for the lexicons of the first and second languages; on the other side, researchers support a theory that storage is separate. This debate also raises questions related to the activation of the bilingual's two languages during lexical production. The present paper reviews two models of bilingual lexical and semantic memory (RHM and $\mathrm{BIA+}$ and the studies associated with the models. The goal is to address whether semantic memory of the bilingual's two languages is represented in an integrated way.

Keywords: Lexical memory; Semantic memory; Bilingual lexicon; Models of bilingual lexical memory.
\end{abstract}

\footnotetext{
${ }^{*}$ Doutoranda do Programa de Pós- Graduação em Inglês: Estudos Linguísticos da Universidade Federal de Santa Catarina.

${ }^{* *}$ Professora do Departamento de Língua e Literatura Estrangeiras da Universidade Federal de Santa Catarina. Bolsista de Produtividade em Pesquisa do CNPq.
} 


\section{Introdução}

As questões que envolvem a memória das palavras de falantes de duas ou mais línguas têm intrigado pesquisadores na área da aprendizagem de língua estrangeira, principalmente porque a literatura fornece diferentes resultados sobre a organização e o processamento do léxico mental de bilíngues. Li (2009) argumenta que os resultados de estudos nesta área de pesquisa têm sido controversos, pois não há conclusão específica quanto à existência de um léxico integrado ou separado para o armazenamento das duas línguas do bilíngue. Ainda de acordo com o autor, dados coletados a partir de pesquisas com neuroimagem têm oferecido resultados relevantes, mas conflitantes, o que tem aumentado o debate sobre o léxico mental de bilíngues.

Gass e Selinker (2008) postulam que o léxico pode ser considerado como o componente mais importante para os aprendizes de uma nova língua. Este argumento se fundamenta em análises de erros de aprendizes de língua estrangeira, que mostram que os erros lexicais, mais frequentes do que os erros gramaticais, podem interferir com a finalidade da comunicação (GASS; SELINKER, 2008).

Francis (2005) argumenta que a organização da memória bilíngue, mais especificamente o grau de integração na representação das duas línguas do bilíngue, é um assunto central nas pesquisas relacionadas ao bilinguismo. Apesar de haver um relativo consenso entre muitos pesquisadores de que as formas lexicais são representadas separadamente para a L1 e a L2 e de que os conceitos e/ou significados destas palavras são armazenados em uma mesma representação, essa pressuposição não é conclusiva nem direta. Evidências de estudos empíricos mostram que vários fatores podem influenciar a representação das palavras, tanto em relação às formas como aos conceitos. Um desses fatores pode ser o nível de proficiência da segunda língua. Outros fatores podem estar relacionados à semelhança entre a L1 e a L2, à presença de cognatos, homógrafos e palavras com pronúncia semelhante.

Kroll e Sunderman (2003) argumentam que os estudos sobre o léxico mental, inicialmente confundiam representação lexical com acesso lexical. De acordo com os autores, a tendência desses estudos era assumir que representações lexicais separadas para as duas línguas implicavam, necessariamente, a ativação seletiva das palavras em apenas uma das línguas. Por outro lado, estudos que partiam da hipótese de um léxico 
integrado para as duas línguas argumentavam também em favor de ativação paralela não seletiva das palavras nas duas línguas. No entanto, Kroll e Sunderman (2003) afirmam que a forma de representação e o modo de acesso do léxico são independentes e, portanto, outras alternativas poderiam ser consideradas.

Ainda em relação à representação mental do léxico, Simos e colaboradores (2005) afirmam que o avanço da tecnologia e a possibilidade da utilização de técnicas não invasivas de neuroimagem têm permitido aos pesquisadores explorar os mecanismos do cérebro que subsidiam as diferentes línguas. No entanto, Illes e colaboradores (1999) argumentam que os resultados dos estudos de neuroimagem não têm convergido para uma única conclusão: ao contrário, enquanto muitos estudos favorecem uma visão de que as múltiplas línguas dos bilíngues são integradas, outros apresentam evidência de diferentes línguas ativando regiões cerebrais distintas.

Esta revisão de literatura busca compreender se há integração ou separação na representação da memória semântica das duas línguas do bilíngue. Para tanto, são apresentados estudos que investigaram os dois modelos de memória lexical e semântica de bilíngues, o RHM e o BIA+, com foco especial nas tarefas de priming semântico. Neste trabalho também foram revisados estudos relacionados à ativação das duas línguas do bilíngue e à representação mental dessas línguas. Na próxima seção são apresentadas questões relacionadas ao priming semântico, método bastante utilizado para investigar a representação lexical e semântica de bilíngues.

\section{Priming semântico}

Priming semântico se refere à facilitação no processamento de uma palavra que foi precedida por outra relacionada em contraposição a uma palavra não relacionada (PHILLIPS et al., 2004). Normalmente esta facilitação é medida pelo tempo de resposta em uma tarefa de decisão lexical que consiste no julgamento de uma sequência de letras como sendo uma palavra verdadeira ou não (PHILLIPS et al., 2004). Além dos estudos comportamentais que utilizam o tempo de reação como medida para avaliar os efeitos de priming semântico, vários estudos têm empregado técnicas de neuroimagem, mais especificamente os potenciais evocados relativos a eventos (Event Related Potentials ERPs). Esta técnica de potenciais evocados permite o registro da atividade elétrica do 
cérebro, em tempo real, através do uso do eletroencefalograma (FEDERMEIER; KUTAS, 1999). Nos estudos que empregam os potenciais evocados, o componente N400 é comumente analisado como a variável dependente, pois este componente é sensível a violações semânticas e dificuldades de integração semântica (FEDERMEIER; KUTAS, 1999). A amplitude do componente N400 varia inversamente à quantidade de ativação semântica que uma palavra tem na memória, ou seja, a amplitude do componente N400 é diminuída quando uma palavra é precedida por um contexto semanticamente relacionado (PHILLIPS et al., 2004).

Duñabeitia e colaboradores (2010) explicam o efeito do priming de tradução (translation priming effect): quando duas palavras da L1/L2 que representam o mesmo conceito são apresentadas ao participante, a leitura da segunda palavra fica mais rápida. Este paradigma de priming de tradução é extensivamente utilizado em estudos de memória lexical e semântica e pode ser aplicado nas duas direções de tradução (L1-L2 e L2-L1). Em tarefas de nomeação de figuras, por exemplo, o prime pode ser apresentado na L2, e a palavra alvo pode ser na L1 do participante. Em teoria, a nomeação da figura na L1 seria facilitada pela apresentação do prime na L2, visto que o prime iria ativar sua representação semântica, que seria comum às duas palavras (prime e palavra alvo). Os pesquisadores alegam também que uma série de fatores afeta o grau de facilitação do reconhecimento da tradução de um não cognato na outra língua, especialmente, o tipo da tarefa, o grau de proficiência na L2 e a direção do priming (de L1 para L2 - ordem direta - ou de L2 para L1 - ordem inversa). Os autores explicam que como a apresentação consciente de um prime e de uma palavra alvo pode gerar uma série de estratégias ao participante, os pesquisadores têm utilizado uma versão mascarada do paradigma de priming de tradução (masked priming translation). Este paradigma mascarado se baseia em estágios automáticos e inconscientes do processamento da palavra e, portanto, não é sujeito a efeitos de estratégia.

Perea, Duñabeitia e Carreiras (2008) explicam que no paradigma de priming mascarado, o prime é apresentado em letra minúscula por aproximadamente 30 a 66 milissegundos (ms) e na sequência o prime é substituído pela palavra alvo, escrita em letra maiúscula. De acordo com os autores, a apresentação do prime sob estas condições faz com que o participante não perceba a identidade do prime podendo, até mesmo, não perceber sua existência. Por esse motivo, os autores afirmam que é improvável que 
algum traço de memória episódica seja criado. Com base nisso, os autores defendem que qualquer efeito de priming de associação semântica reflete processos automáticos, e não processos de estratégia. No caso dos primes visíveis, os autores afirmam que o tempo de apresentação é em torno de 200 ms.

Na seção 3 deste artigo dois modelos de memória lexical bilíngue, o RHM e o BIA+, são discutidos. De acordo com Perea, Duñabeitia e Carreiras (2008), estes modelos estão entre os mais investigados na literatura de representação lexical e semântica de bilíngues, principalmente dentre os estudos envolvendo priming semântico.

\section{Modelos de memória lexical de bilíngues}

Alvarez, Holcomb e Grainger (2003) argumentam que as teorias de processamento lexical de bilíngues normalmente dividem a representação de palavras e conceitos em níveis lexical e conceitual, onde este último consiste da representação dos significados. De acordo com Heredia e Brown (2012), esta distinção entre os níveis lexical e conceitual foi mencionada pela primeira vez na obra de Weinreich (1953 apud HEREDIA; BROWN, 2012). Alvarez, Holcomb e Grainger (2003) explicam que, na visão hierárquica do léxico bilíngue, no nível lexical, há uma separação entre L1 e L2, porém, no nível conceitual, L1 e L2 estão integradas. Dentro dessa visão hierárquica do léxico bilíngue, os primeiros modelos hierárquicos propostos foram o modelo de associação (word association model) e o modelo de mediação conceitual (concept mediation model) (HEREDIA; BROWN, 2012).

0 modelo de associação prevê que o acesso dos conceitos das palavras da L2 ocorre através de links lexicais com as palavras da L1, enquanto o modelo de mediação conceitual propõe que em cada língua há acesso direto aos conceitos (ALVAREZ; HOLCOMB; GRAINGER, 2003).

Com a finalidade de investigar esses dois modelos, Kroll e Stewart (1994) conduziram um estudo com bilíngues que consistia de três tarefas: nomeação de figuras, nomeação de palavras e tradução. Os resultados desse estudo mostraram que as palavras eram nomeadas mais rapidamente do que as suas figuras correspondentes. Os resultados mostraram também que a recuperação do nome das figuras era influenciada pelo contexto semântico, enquanto a recuperação de palavras não era, sugerindo que a 
nomeação de figuras requer mediação conceitual, mas a nomeação de palavras não. Ainda em relação ao estudo de Kroll e Stewart (1994), as pesquisadoras observaram que a tradução da L2 para a L1 era mais rápida do que a tradução da L1 para a L2, pois a primeira é realizada com uma base lexical, enquanto a segunda requer mediação conceitual. De acordo com os resultados desse estudo, Kroll e Stewart (1994) propuseram o Modelo Hierárquico Revisado (Revised Hierarcquical Model - RHM), o qual postula que o acesso ao significado das palavras da L2 é mediado por ligações lexicais com as palavras da L1 no estágio inicial da aprendizagem da L2. Porém, com o aumento da proficiência, as palavras da L2 passam a ser acessadas diretamente aos seus conceitos. Este modelo (RHM) foi proposto para explicar as assimetrias nas traduções L1-L2, pois traduções na direção da L1 para a L2 demorariam mais do que na direção inversa (L2-L1). De acordo com o modelo, a explicação para esta assimetria é o fato da tradução L1-L2 ser conceitualmente mediada, enquanto a tradução L2-L1 é lexicalmente mediada.

Outra classe de modelos de memória lexical de bilíngues são os modelos interativos, os quais propõem que ativação em uma unidade dos três níveis de representação (ortográfico, fonológico e semântico) irá consequentemente ativar unidades nos outros dois níveis (SILVERBERG; SAMUEL, 2004). Dijskstra e Van Heuven (2002) propuseram o modelo BIA+ como extensão do modelo de Ativação Interativa Bilíngue (Bilingual Interactive Activation - BIA). 0 modelo inicial, BIA (DIJSKSTRA; VAN HEUVEN, 1998, apud DIJSKSTRA; VAN HEUVEN, 2002), foi proposto para explicar o reconhecimento ortográfico das representações das palavras. A extensão deste modelo $(\mathrm{BIA}+)$ incluiu representações fonológicas e semânticas para as palavras, incluiu também a representação de homógrafos interlinguísticos e ainda explicações para como o contexto linguístico e não linguístico afetam o reconhecimento das palavras.

Adicionalmente, o modelo BIA+ traz detalhes sobre o desempenho de bilíngues em tarefas, como, por exemplo, decisão lexical e a relação entre identificação de palavras e exigências da tarefa. 0 modelo BIA+ é um modelo computacional, concebido para explicar reconhecimento das palavras por bilíngues. Este modelo postula que, quando uma sequência de letras é visualizada, palavras que contêm características na mesma posição das letras apresentadas serão ativadas nas duas línguas do bilíngue. $\mathrm{Na}$ sequência, palavras ortograficamente candidatas ativam suas representações 
fonológicas e semânticas. Esse modelo prevê que o reconhecimento de palavras por bilíngues é afetado translinguisticamente, por efeitos similares, nos níveis ortográfico, fonológico e semântico. Este modelo também sustenta a visão de um léxico integrado para as duas línguas do bilíngue e acesso lexical não seletivo. Dijkstra (2005) argumenta que o reconhecimento de palavras envolve a ativação de candidatos lexicais em diferentes línguas; isto significa que há ativação paralela para o reconhecimento de palavras de bilíngues.

De acordo com Kroll e Tokowicz (2005) o modelo BIA+ é o modelo de forma de palavras mais extensivamente investigado na literatura. A próxima seção consiste de estudos que investigaram os modelos de memória lexical RHM e BIA+.

\section{Estudos que investigaram os modelos de memória lexical RHM e BIA+}

O primeiro estudo revisado nesta seção é o de Sholl, Sankaranarayanan e Kroll (1995), o qual foi conduzido logo após a proposição do modelo RHM. Neste estudo, os pesquisadores investigaram a relação entre nomeação de figuras e tradução, utilizando um paradigma de transferência. Para tanto, bilíngues falantes de inglês e espanhol foram solicitados a nomear figuras e consequentemente traduzir palavras nas suas primeira e segunda línguas, sendo que algumas palavras dessa tarefa de tradução eram repetições de conceitos previamente nomeados como figuras. Os resultados do estudo mostraram que a nomeação de figuras produziu transferência para a tradução de L1 para L2, mas não para a tradução de L2 para L1. Dessa forma, os resultados do estudo sustentam o argumento de que as conexões na memória bilíngue são assimétricas, sendo que a tradução de L1 para L2 é conceitualmente mediada, enquanto a tradução de L2 para L1 é lexicalmente mediada. Os resultados mostram também que o acesso conceitual pode produzir transferência entre as línguas. De acordo com os autores, há ainda uma assimetria nos efeitos de priming de L1 e L2, sendo que a evidência deste estudo é de que apenas a L1 facilita a nomeação da L2. 0 estudo sustenta também o argumento geral de que tarefas que requerem um processamento conceitual compartilhado facilitam uma à outra. Os resultados do estudo dão suporte ao modelo RHM.

Nove anos após a proposição do modelo RHM, Alvarez, Holcomb e Grainger (2003), conduziram um estudo com base no modelo, para investigar a organização e o 
processamento das palavras da L1 e L2 de bilíngues precoces. Neste estudo, potenciais evocados (ERPs) foram utilizados enquanto os participantes desempenhavam uma tarefa semântica de detecção de palavras (semantic word detection task), tendo o N400 como variável dependente. 0 componente N400 foi a variável dependente do estudo, visto que este componente é sensível a repetições de palavras durante a tarefa; palavras repetidas durante um experimento podem causar uma amplitude menor no componente N400. Os autores acrescentam ainda que os efeitos de repetição podem ser vistos no ERP em uma fase anterior e/ou posterior ao N400.

Dessa forma, o estudo de Alvarez, Holcomb e Grainger (2003) foi desenhado para comparar efeitos de repetição dentro da mesma língua e entre duas línguas do bilíngue. 0 experimento consistia em uma tarefa de categorização semântica, na qual uma sequência de palavras em inglês e espanhol eram apresentadas. Esta sequência incluía repetições de palavras previamente apresentadas, tanto dentro da mesma língua como entre as duas línguas. Os participantes tinham que ler as palavras apresentadas e pressionar um botão para responder se a palavra se referia a alguma parte do corpo humano em uma das línguas. De acordo com os autores, a comparação dos efeitos de repetição das palavras de uma mesma língua e de línguas diferentes no N400 deveria informar sobre a interação entre forma e significado na geração desses efeitos. De acordo com o modelo RHM, uma palavra da L2 automaticamente ativa a representação da forma da palavra na L1, mas não ativa o significado compartilhado das palavras na L1 e L2. Por outro lado, palavras na L1 não ativam automaticamente a representação da forma equivalente na L2, mas ativam a representação de significado compartilhada entre L1 e L2. Os resultados do estudo favoreceram o RHM, pois o efeito de priming foi mais rápido na ordem de apresentação L2-L1 do que quando uma palavra na L2 seguia a sua tradução equivalente na L1. Neste último caso, os autores explicam que há uma operação adicional, onde a palavra na L2 tem que primeiro ativar o equivalente na L1, resultado que no ERP equivale a um atraso no componente N400.

O estudo de Phillips et al., (2004) investigou o priming semântico da L2 utilizando uma tarefa de classificação semântica, partindo do pressuposto de que esta tarefa é mais parecida com a vida real das pessoas, onde é mais comum lidar com palavras em relação ao significado do que avaliar palavras ou não palavras, como nas tarefas de decisão lexical. 0 estudo consistiu de dois experimentos com ERPs e medidas de tempo de 
reação, ambos desempenhados por participantes falantes nativos de inglês e falantes de francês como L2, com nível de proficiência variável. Os resultados do estudo mostraram que os participantes altamente proficientes na L2 mostraram evidência dos efeitos de priming tanto na L1 como na L2 para tempo de reação e ERP. No entanto, os participantes com baixo nível de proficiência na L2 mostraram efeitos de priming na L1 e na L2 em relação ao tempo de resposta, mas em relação ao ERP, apenas na L1 foi encontrado efeito de priming. Os autores afirmam que os resultados trazem evidência de que as medidas de tempo de reação e ERPs avaliam estágios diferentes do processamento lexical e semântico. A medida do tempo de reação para o efeito de priming está relacionada com processos automáticos de ativação que acontecem durante o acesso lexical, e o componente N400 está relacionado a processos de integração póslexical. Esses processos de integração pós-lexical constituem a parte final do processo de compreensão, onde o significado de cada palavra encontra sua representação no sentido geral da sentença (BROWN; HAGOORT; KUTAS, 2000). Nesta etapa do processo de compreensão, papéis temáticos, tais como de agente, tema e paciente são estabelecidos para a sentença (BROWN; HAGOORT; KUTAS, 2000).

Os resultados do estudo de Phillips et al., (2004) também mostraram um atraso de $50 \mathrm{~ms}$ no efeito do componente $\mathrm{N} 400$ para a L2 dos bilíngues altamente proficientes, em comparação com a L1 desses bilíngues. De acordo com os autores, este resultado é consistente com a ideia de que o processamento da L2 é mais lento do que da L1, pela necessidade de se acessar as palavras da L2 através do léxico da L1, conforme previsto pelo modelo RHM.

Por outro lado, o estudo de Kerkhofs e colaboradores (2006) investigou o modelo BIA+. Mais especificamente, o estudo investigou o processamento da ambiguidade existente entre homógrafos das duas línguas de bilíngues no reconhecimento de palavras. Neste estudo, bilíngues altamente proficientes de holandês-inglês realizaram uma tarefa de decisão lexical, onde os homógrafos na segunda língua do participante eram precedidos por um item semanticamente relacionado ou não relacionado. Os resultados do estudo mostraram que primes relacionados geraram uma amplitude menor no componente N400 do que os primes não relacionados, favorecendo a visão do acesso lexical como não seletivo e também a visão do léxico bilíngue acessado paralelamente por duas línguas. Os resultados favorecem o modelo BIA+ de 
reconhecimento de palavras e uma extensão do modelo, proposta por Kerkhofs e colaboradores (2006), para priming semântico de bilíngues, o qual propõe que, de acordo com o modelo $\mathrm{BIA}^{+}$, o processo de reconhecimento de palavras pode ser afetado pelo contexto linguístico.

Esta extensão do modelo BIA+, proposta por Kerkhofs e colaboradores (2006), consiste em um modelo de priming semântico para descrever como as representações léxico-ortográficas e semânticas de diferentes línguas interagem no caso dos homógrafos interlinguísticos. Os autores afirmam que dentro da visão não seletiva do léxico, estudos têm demonstrado que acesso ao léxico mental do bilíngue envolve todas as palavras, tanto da L1 como da L2. Ainda de acordo com os autores, o modelo BIA prevê que o reconhecimento de um homógrafo interlinguístico envolve a ativação paralela da leitura deste homógrafo nas duas línguas do bilíngue. Assim, de acordo com a extensão do modelo, em uma condição de priming semântico, onde um homógrafo interlinguístico é precedido por um prime semanticamente relacionado, a palavra alvo pode ser reconhecida mais rapidamente, já que o prime pode pré-ativar a representação do significado da palavra alvo e induzir a um reconhecimento mais rápido.

Com a finalidade de avaliar se a aquisição natural e precoce da segunda língua tem um efeito no acesso semântico das palavras da L2, o estudo de Perea, Duñabeitia e Carreiras (2008) teve como participantes bilíngues altamente proficientes em basco e espanhol. A tarefa aplicada neste estudo foi uma decisão lexical. Os autores afirmam que tanto o RHM quanto o modelo $\mathrm{BIA}^{+}$preveem a existência de efeitos de priming semântico precoce e automáticos. Os resultados deste estudo mostraram que bilíngues simultâneos, falantes de basco e espanhol, demonstram efeitos de priming de associação semântica automática e precoce para pares de palavras não cognatas em uma tarefa de decisão lexical. Os resultados são verdadeiros tanto entre as duas línguas como dentro da mesma língua.

0 mesmo efeito foi obtido para bilíngues tardios altamente proficientes. Mais especificamente, os resultados dos três experimentos conduzidos neste estudo mostraram que há efeito de priming semântico entre as línguas do bilíngue e que este processo acontece cedo e de forma automática. De acordo com os autores, os resultados deste estudo favorecem uma visão de um modelo de memória bilíngue com a proficiência como fator de hierarquia, como o RHM, onde a integração semântica da L1 e 
da L2 ocorre conforme o aumento da proficiência. Nesta visão, bilíngues altamente proficientes tem acesso a uma memória conceitual/ semântica compartilhada para as duas línguas (PEREA; DUÑABEITIA; CARREIRAS, 2008). Os autores afirmam ainda que os resultados do estudo são compatíveis também com o modelo $\mathrm{BIA}^{+}$, pois este modelo prevê a presença de efeitos precoces de priming semântico.

O estudo de Palmer, Van Hooff e Havelka (2010) utilizou ERPs para testar as suposições do modelo RHM e investigar a ativação semântico-lexical durante uma tarefa de tradução. Nesse experimento, bilíngues tardios dos pares espanhol-inglês e inglêsespanhol, tendo a L1 como dominante, realizaram uma tarefa de tradução, onde eles se deparavam com pares de palavras e tinham que responder se elas tinham ou não o mesmo significado. A tarefa era baseada em um paradigma de tradução (translation condition paradigm). As palavras incluídas no estudo eram tanto substantivos concretos como abstratos. Os resultados de ERPs do estudo favoreceram uma visão assimétrica da tradução L1-L2 e L2-L1, pois o efeito do N400 foi maior para tradução L2-L1 do que L1L2. Os resultados também mostraram que o fato do substantivo ser concreto ou abstrato não teve influência na tarefa. Os resultados dos ERPs para os dois experimentos corroboram uma visão assimétrica na mediação da tradução L1-L2 e L2-L1. De fato, os resultados do estudo dão suporte ao RHM.

Duñabeitia e colaboradores (2010) postulam que, apesar de muitos estudos terem demonstrado que há uma assimetria na ativação das duas línguas do bilíngue, com o efeito de priming na ordem direta sendo maior que na ordem inversa em tarefas de decisão lexical, há fatores que podem interferir nesses resultados. No caso de tarefas de categorização semântica, por exemplo, os efeitos de priming parecem ser simétricos. Já em tarefas de reconhecimento episódico, o efeito aparece apenas na ordem inversa. Em relação à proficiência na $\mathrm{L} 2$, os autores colocam que há evidência de que o aumento da proficiência diminui a assimetria observada nos efeitos de priming nas ordens direta e inversa. Os autores acrescentam ainda que estas suposições são consistentes com o modelo RHM. Contudo, argumentam que os efeitos de priming mascarado de tradução (masked priming translation) são mais bem explicados pelo modelo BIA+, o qual prevê que em níveis baixos e intermediários de proficiência, as palavras da L2 se encontram menos ativas, se comparadas com as palavras da L1, devido à pouca frequência de uso. Portanto, palavras da L2 precisam de maior ativação para o processo de reconhecimento 
e este processo, consequentemente, leva mais tempo.

O estudo de Duñabeitia et al., (2010) utilizou ERPs para avaliar os efeitos de priming mascarado de tradução em bilíngues simultâneos de espanhol e basco, com o mesmo nível de proficiência nas duas línguas. Os resultados do estudo mostraram efeitos simétricos do N400 nas duas direções de tradução. Os resultados sugerem que, neste nível de proficiência, o acesso aos conceitos é feito de forma direta para as duas línguas do bilíngue. Dessa forma, o estudo favorece o modelo $\mathrm{BIA}^{+}$, diante da proposição da diminuição da diferença de ativação entre as palavras da L1 e da L2 com o aumento da proficiência.

\section{Ativação da L1 e L2, acesso lexical e representação mental do léxico}

Bialystok, Craik e Luk (2008) argumentam que o acesso lexical é mais difícil para os bilíngues do que para os monolíngues, em função da ativação conjunta das duas línguas do bilíngue durante o processo de produção de uma língua alvo. Por esse motivo, os autores afirmam que para os bilíngues há a necessidade de seleção ou atenção para a língua alvo. Desse modo, a necessidade de controlar a interação das duas línguas de forma que elas não interfiram na produção da língua alvo, resulta no desenvolvimento de uma capacidade maior de monitoramento de atenção e de seleção para os bilíngues, vantagem esta sustentada nos resultados empíricos fornecidos por uma série de estudos de Bialystok e colaboradores (BIALYSTOK, 1999; BIALYSTOK et al., 2004; BIALYSTOK; CRAIK; RYAN, 2006; EMMOREY, 2008; MARTIN-RHEE; BIALYSTOK, 2008).

De acordo com Bialystok, Craik e Luk (2008), a memória de trabalho também deve ser maior para os bilíngues, já que estes precisam administrar duas línguas. Assim, o desenvolvimento da memória de trabalho seria outra vantagem sustentada pelos autores para os falantes bilíngues. No entanto, os autores argumentam que uma consequência de administrar duas línguas é a dificuldade encontrada no acesso lexical de bilíngues. Os autores afirmam que essa dificuldade de acesso não acontece em relação à informação semântica. Os autores argumentam ainda que o conflito lexical resultante da ativação conjunta das duas línguas do bilíngue é solucionado pelo mesmo mecanismo de seleção de atenção dos lobos frontais que são utilizados também para processamento executivo em geral. Portanto, segundo Bialystok, Craik e Luk (2008), o conflito lexical 
produzido pela ativação conjunta das duas línguas do bilíngue tem um efeito benéfico no aprimoramento de processos de controle utilizados para resolução de conflitos, mas tem a desvantagem de reduzir a eficiência do acesso ou da recuperação das palavras em uma das línguas do bilíngue.

Colomé e Miozzo (2010) sustentam também a posição da ativação conjunta das duas línguas do bilíngue e argumentam que pesquisas com foco em participantes bilíngues têm demonstrado que a produção de palavras não envolve apenas a ativação da palavra pretendida. Os autores afirmam que o processo de seleção lexical para bilíngues é muito mais caótico, pois muitas palavras são ativadas simultaneamente configurando-se como potenciais candidatos à interferência na seleção lexical. De acordo com os autores, há muitos fatores que levam à ativação conjunta destas múltiplas palavras, dentre eles, são destacados a relação semântica das palavras candidatas com a pretendida, a semelhança fonética entre as palavras, a distração do falante em relação à tarefa sendo desempenhada ou ainda o planejamento da utilização de uma palavra posteriormente no discurso. Os autores afirmam que estes fatores interferem tanto na produção lexical de bilíngues como monolíngues, mas, no caso de bilíngues, o processo de produção de palavras pode ser ainda mais complexo, devido à ativação do léxico das duas línguas.

Dessa forma, o estudo de Colomé e Miozzo (2010) buscou investigar a natureza da ativação das palavras na língua não pretendida através do paradigma de interferência figura-figura. Nesta tarefa, os participantes visualizam pares de figuras sobrepostas e devem nomear apenas uma das figuras, ignorando a outra. As figuras utilizadas na tarefa continham diferentes tipos de nomes, como cognatos e nomes semelhantes entre as duas línguas. Havia figuras como distratores, que não continham nomes cognatos e nem relacionados com a outra língua, as quais serviram de controle. Os participantes do estudo eram bilíngues altamente proficientes de espanhol e catalão. Os resultados do estudo sugeriram que as palavras não pretendidas na língua que não está sendo utilizada também são ativadas ao mesmo tempo em que as palavras alvo da língua utilizada. Mais especificamente, os resultados sugerem que a ativação de palavras não se restringe às traduções da palavra alvo, mas também ao nome de outras palavras presentes no contexto. Adicionalmente, a ativação das palavras se estende às características fonológicas das palavras na língua não pretendida. 
Com o objetivo de investigar a ativação de múltiplos itens lexicais de bilíngues, Marian, Spivey e Hirsch (2003) realizaram um experimento utilizando rastreamento ocular com bilíngues falantes de russo e inglês. Os resultados deste estudo mostraram que há competição dos itens lexicais inter e intralinguísticamente. Dessa forma, os resultados do estudo sugerem que mesmo quando o ambiente é monolíngue, o insumo fonológico das palavras é simultaneamente ativado no léxico da L1 e L2 do bilíngue. Um estudo de Titone et al. (2011) também mostrou que as palavras da L2 do bilíngue eram ativadas enquanto os participante desempenhavam uma tarefa de leitura exclusivamente na L1. De acordo com os autores, estes resultados favorecem uma visão não seletiva para o léxico de bilíngues precoces, favorecendo também uma visão de um armazenamento integrado para os léxicos de L1 e L2.

Com o objetivo de investigar as diferenças e semelhanças no processamento das línguas do bilíngue e a ativação no cérebro destas línguas, foi conduzido um estudo (MARIAN; SPIVEY; HIRSCH, 2003) com IRMf (Imagens de Ressonância Magnética funcional). Os participantes deste estudo foram bilíngues falantes de russo e inglês. Os resultados do estudo, em relação às semelhanças no processamento das duas línguas mostraram que o processamento lexical e fonológico das duas línguas envolve as mesmas áreas corticais. Porém, algumas diferenças no processamento das duas línguas também foram encontradas: a segunda língua ativou áreas corticais maiores do que a primeira língua, sugerindo que bilíngues tardios recrutam um maior número de áreas corticais para o processamento da L2. Em relação ao processamento das duas línguas do bilíngue, os resultados do estudo favorecem a posição do acesso paralelo para as duas línguas, indicando que mesmo quando apenas uma língua é exigida para uso, as duas línguas são ativadas em paralelo.

Li (2009) argumenta em favor do efeito da idade de aquisição da segunda língua como determinante na organização do léxico de L1 e L2. De acordo com o autor, no caso da aquisição simultânea de L1 e L2, o léxico das duas línguas pode competir um com o outro. No caso da aprendizagem precoce da L2, o cérebro está disponível para mudanças, pois ainda é suficientemente plástico, portanto, há competição do vocabulário da L2 com o léxico da L1, resultando no estabelecimento de territórios independentes para o vocabulário da L2. No entanto, quando a aprendizagem da L2 ocorre mais tarde, as representações da L1 já estão consolidadas e consequentemente as 
palavras da L2 utilizam as estruturas e conexões cerebrais previamente estabelecidas para a L1. Em contraposição, Simos e colaboradores (2005) argumentam que, apesar dos muitos estudos conduzidos com o propósito de investigar a influência dos fatores de idade de aquisição e proficiência na organização cerebral da L1 e L2, os resultados apresentados na literatura ainda são inconclusivos.

De acordo com Hickok (2009), a organização das palavras nos níveis semântico/ conceitual ainda é um assunto de debate, pois os resultados da literatura são muito controversos. Francis (1999), por outro lado, argumenta que há grande evidência favorecendo a visão de um sistema conceitual único subsidiando as duas línguas do bilíngue. Illes et al. (1999), em um estudo com bilíngues proficientes falantes dos pares linguísticos inglês-espanhol e espanhol-inglês sugerem, com base nos resultados apresentados de que as duas línguas ativaram as mesmas regiões corticais, que o processamento semântico no cérebro bilíngue é mediado por sistemas neurais comuns às duas línguas.

Isel et al. (2010), em um estudo com foco no nível conceitual, investigaram os efeitos de idade de aquisição na representação semântico-conceitual de substantivos concretos na segunda língua. Os autores aplicaram uma tarefa de categorização semântica, utilizando pares de substantivos concretos em francês-alemão para manipular efeitos de repetição de priming interlinguisticamente, entre L1 e L2. Os resultados do estudo mostraram um efeito de priming significativamente maior para os bilíngues tardios do que para os bilíngues precoces. Com base nestes resultados, os autores concluem a favor da visão de uma representação conceitual compartilhada para bilíngues precoces e tardios. Contudo, os autores observaram, através do uso de fMRI, que idade de aquisição afeta a representação semântico-conceitual das palavras de L1 e L2, sugerindo que a aquisição lexical também é afetada pela maturação neural.

\section{Conclusão}

Com base nos dados empíricos apresentados nesta revisão de literatura, sugerese que a existência de uma memória integrada ou compartilhada para as duas línguas do bilíngue não seja uma questão tão direta, como se acreditava nos primeiros estudos sobre o léxico mental. Contrariamente, parece que falar sobre o grau de integração ou de 
separação do léxico é mais apropriado, principalmente devido ao grande número de fatores que influenciam esta organização mental, dentre os quais, foram mencionados nos estudos revisados no presente trabalho, o nível de proficiência da L2, a idade e a forma de aquisição dessa segunda língua. Outros fatores linguísticos também mencionados nos estudos revisados seriam relativos à semelhança ortográfica, fonológica e/ou semântica entre as duas línguas do bilíngue, os quais resultariam na presença de cognatos, homógrafos, ou ainda palavras com o mesmo significado e forma diferentes, e também com formas diferentes, mas pronúncias semelhantes. A sobreposição dessas características linguísticas pode ser um fator de influência na organização mental do léxico das primeiras e segundas línguas, porém, não há consenso na literatura sobre essas questões.

Devem ser mencionado também os modelos de memória bilíngue RHM e BIA+, explorados neste trabalho, por serem extensivamente investigados na literatura. Os estudos empíricos revisados fornecem evidência em favor dos dois modelos. Sholl, Sankaranarayanan e Kroll (1995) encontraram sustentação para o modelo RHM, em relação à assimetria nos efeitos de priming da L1 e da L2. Com o auxílio de ERPs, Alvarez, Holcomb e Grainger (2003) também obtiveram resultados assimétricos de priming da L1 e da L2, favorecendo também o modelo RHM. Este modelo também foi favorecido por Phillips et al. (2004), visto que no estudo observou-se que o processamento da L2 é mais lento do que o da L1, devido a necessidade de acessar os conceitos através da L1. Palmer, Van Hooff e Havelka (2010), utilizando ERPs, também favoreceram o modelo RHM devido à assimetria de tradução L1-L2 e L2-L1.

0 modelo BIA+ foi favorecido pelos estudos de Kerkhofs et al. (2006) e Duñabeitia et al. (2010), ambos com o auxílio de ERPs. O estudo de Kerkhofs et al. (2006) favoreceu a visão do acesso lexical como não seletivo e também a visão do léxico bilíngue acessado paralelamente por duas línguas, conforme proposto pelo modelo BIA+. Duñabeitia et al. (2010) também favoreceram o modelo BIA+, pois obtiveram resultados de efeitos simétricos do componente N400 nas duas direções de tradução para bilíngues simultâneos.

Por outro lado, o estudo de Perea, Duñabeitia e Carreiras (2008) favoreceu tanto o modelo RHM quanto o BIA+. Este é um resultado interessante, pois, apesar dos modelos servirem a diferentes propósitos - o RHM é um modelo de produção lexical, 
mais especificamente voltado para a tradução, ao passo que o BIA+ é um modelo de reconhecimento das palavras - eles não devem ser vistos como opostos, mas sim como complementares, visto que a área de pesquisa sobre o léxico mental é muito complexa e que a literatura só se beneficia com as explicações e modelos propostos sob diferentes perspectivas.

\section{Referências}

ALVAREZ, Ruben P.; HOLCOMB, Phillip J.; GRAINGER, Jonathan. Accessing word meaning in two languages: An event-related brain potential study of beginning bilinguals. Brain and Language, v. 87, n. 2, p. 290-304, 2003.

BIALYSTOK, Ellen. Cognitive complexity and attentional control in the bilingual mind. Child development, v. 70, n. 3, p. 636-644, 1999.

BIALYSTOK, Ellen et al. Bilingualism, aging, and cognitive control: evidence from the Simon task. Psychology and aging, v. 19, n. 2, p. 290, 2004.

BIALYSTOK, Ellen; CRAIK, Fergus; LUK, Gigi. Cognitive control and lexical access in younger and older bilinguals. Journal of Experimental Psychology: Learning, Memory, and Cognition, v. 34, n. 4, p. 859, 2008.

BIALYSTOK, Ellen; CRAIK, Fergus I.M.; RYAN, Jennifer. Executive control in a modified antisaccade task: Effects of aging and bilingualism. Journal of Experimental Psychology: Learning, Memory, and Cognition, v. 32, n. 6, p. 1341, 2006.

BROWN, Colin M.; HAGOORT, Peter; KUTAS, Marta. Postlexical integration processes in language comprehension: evidence from Brain-Imaging research. In: GAZZANIGA, M. S. (Ed.). The new cognitive neurosciences. 2. ed., 2000, p. 881-895.

COLOMÉ, Àngels; MIOZZO, Michele. Which words are activated during bilingual word production? Journal of Experimental Psychology: Learning, Memory, and Cognition, v. 36, n. 1, p. 96, 2010.

DIJKSTA, T. Bilingual visual word recognition and lexical access. In: KROLL, Judith F.; DE GROOT, Annette (Orgs.). Handbook of bilingualism psycholinguistic approaches. Oxford University Press, v. 54, 2005, p. 179-201.

DIJKSTRA, A. F. J.; HEUVEN, WJB van. The architecture of the bilingual word recognition system: From identification to decision. Bilingualism: Language and Cognition, v. 5, n. 3, p. $175-197,2002$.

DUÑABEITIA, Jon Andoni et al. Electrophysiological correlates of the masked translation priming effect with highly proficient simultaneous bilinguals. Brain research, v. 1359, p. 142-154, 2010. 
EMMOREY, Karen et al. The Source of Enhanced Cognitive Control in Bilinguals Evidence From Bimodal Bilinguals. Psychological Science, v. 19, n. 12, p. 1201-1206, 2008.

FEDERMEIER, Kara D.; KUTAS, Marta. Right words and left words: Electrophysiological evidence for hemispheric differences in meaning processing. Cognitive Brain Research, v. 8, n. 3, p. 373-392, 1999.

FRANCIS, Wendy S. Cognitive integration of language and memory in bilinguals: semantic representation. Psychological bulletin, v. 125, n. 2, p. 193, 1999.

FRANCIS, Wendy S. Bilingual semantic and conceptual representation. In: KROLL, Judith F.; DE GROOT, Annette (Orgs.). Handbook of bilingualism: Psycholinguistic approaches. Oxford University Press, 2005, v. 54, p. 251, 2005.

GASS, Susan M.; SELINKER, Larry. Second language acquisition: An introductory course. Routledge, 2008.

HEREDIA, ROBERTO R.; BROWN, JEFFREY M. Bilingual Memory. In: BHATIA, Tej K.; RITCHIE, William C. (Orgs.). The handbook of bilingualism and multilingualism. WileyBlackwell, 2012, p. 269-291.

HICKOK, Gregory. The functional neuroanatomy of language. Physics of life reviews, v. 6, n. 3, p. 121-143, 2009.

ILLES, Judy et al. Convergent cortical representation of semantic processing in bilinguals. Brain and language, v. 70, n. 3, p. 347-363, 1999.

ISEL, Frédéric et al. Neural circuitry of the bilingual mental lexicon: Effect of age of second language acquisition. Brain and cognition, v. 72, n. 2, p. 169-180, 2010.

KERKHOFS, Roel et al. Testing a model for bilingual semantic priming with interlingual homographs: RT and N400 effects. Brain Research, v. 1068, n. 1, p. 170-183, 2006.

KROLL, Judith F.; STEWART, Erika. Category interference in translation and picture naming: Evidence for asymmetric connections between bilingual memory representations. Journal of memory and language, v. 33, n. 2, p. 149-174, 1994.

KROLL, Judith F.; SUNDERMAN, Gretchen. Cognitive processes in second language learners and bilinguals: The development of lexical and conceptual representations. In: DOUGHTY, Catherine J.; LONG, Michael H. The handbook of second language acquisition, 2003, p. 104-129

KROLL, Judith F; TOKOWICZ, Natasha. Models of bilingual representation and processing. In: KROLL, Judith F.; DE GROOT, Annette (Orgs.). Handbook of bilingualism: Psycholinguistic approaches. Oxford University Press, 2005, v. 54, p. 531-553.

LI, Ping. Lexical organization and competition in first and second languages: 
Computational and neural mechanisms. Cognitive science, v. 33, n. 4, p. 629-664, 2009.

MARIAN, Viorica; SPIVEY, Michael; HIRSCH, Joy. Shared and separate systems in bilingual language processing: Converging evidence from eyetracking and brain imaging. Brain and language, v. 86, n. 1, p. 70-82, 2003.

MARTIN-RHEE, Michelle M.; BIALYSTOK, Ellen. The development of two types of inhibitory control in monolingual and bilingual children. Bilingualism Language and Cognition, v. 11, n. 1, p. 81, 2008.

PALMER, Shekeila D.; VAN HOOFF, Johanna C.; HAVELKA, Jelena. Language representation and processing in fluent bilinguals: Electrophysiological evidence for asymmetric mapping in bilingual memory. Neuropsychologia, v. 48, n. 5, p. 1426-1437, 2010.

PEREA, Manuel; DUÑABEITIA, Jon Andoni; CARREIRAS, Manuel. Masked associative/semantic priming effects across languages with highly proficient bilinguals. Journal of Memory and Language, v. 58, n. 4, p. 916-930, 2008.

PHILLIPS, Natalie A. et al. Semantic priming in a first and second language: evidence from reaction time variability and event-related brain potentials. Journal of Neurolinguistics, v. 17, n. 2, p. 237-262, 2004.

SHOLL, Alexandra; SANKARANARAYANAN, Aruna; KROLL, Judith F. Transfer between picture naming and translation: A test of asymmetries in bilingual memory. Psychological Science, v. 6, n. 1, p. 45-49, 1995.

SILVERBERG, Stu; SAMUEL, Arthur G. The effect of age of second language acquisition on the representation and processing of second language words. Journal of Memory and Language, v. 51, n. 3, p. 381-398, 2004.

SIMOS, P. G. et al. Brain mechanisms supporting distinct languages. Learning Disabilities Research \& Practice, v. 20, n. 1, p. 31-38, 2005.

TITONE, Debra et al. Bilingual lexical access during L1 sentence reading: The effects of L2 knowledge, semantic constraint, and L1-L2 intermixing. Journal of Experimental Psychology: Learning, Memory, and Cognition, v. 37, n. 6, p. 1412, 2011.

Recebido em dezembro de 2013.

Aceito em abril de 2014. 